\title{
Place of the transobturator tape technique (TOT) in the management of stress urinary incontinence in women
}

\author{
Mohammed Mrabti, Mohamed Tetou, Jendouzi Omar, Boukhlifi Youness, Khdach Youness, Bahri Abdessamad, Louardi Nabil, Alami Mo- \\ hammed, Ameur Ahmed and Abbar Mohamed \\ Military Hospital Mohammed V, Rabat, Morocco
}

\begin{abstract}
Objective: The rational of the surgical treatment of female stress urinary incontinence has changed over the past few years. The techniques of colposuspension have been replaced by the suburethral slings, retropubic initially with the TVT and then, the suburethral transobturator tape (TOT), introduced to reduce the complications of the TVT. It is thus difficult to currently have an objective idea of the effectiveness of the TOT compared to the TVT, even if the first impressions, with respect to the TOT, are rather favourable. The objective of this study is to present the feasibility, short- and long-term results of the surgical treatment of stress urinary incontinence by TOT tape.
\end{abstract}

Materials and methods: This retrospective study involved all patients who were surgically treated for incontinence by TOT tape according to the OUT-IN method, based on polypropylene monofilament sling.

Results: Two hundred patients were involved. All patients were urodynamically diagnosed with stress urinary incontinence. Renal and bladder ultrasound was systematically requested in order to avoid any anomalies of the lower urinary tract. The mean duration of intervention is 25 minutes, and a duration of hospitalization between 3 and 5 days. $82 \%$ of patients regained normal continence with no evidence of urgency with improvement of quality of life. Only 15 cases of dysuria were reported that regressed spontaneously, 11 cases of vaginal erosion and only two cases of de novo-urge.

Conclusion: The TOT is an excellent procedure for the definitive surgical treatment, given that the results are satisfactory, whether anatomically or functionally.

\section{Introduction}

Stress urinary incontinence (SUI) is a pathology due to the deterioration of the muscles and ligaments supporting the urethra and the bladder neck [1], Although SUI cannot be life-threatening, it still seriously affects the quality of life of female on social, psychological, physical, domestic, and sexual function [2].

Since the event of the tension free vaginal tape (TVT), in 1996 by Ulmsten [3], the management of the UIE has changed. It has become the most commonly performed operation [4], with a long-term success between $84 \%$ and $94 \%$ [5], however, it is associated with an increased risk of digestive and bladder perforation, injury of large vessels and also to acute retention of urine [6].

In France in 2001, Delorme introduced the transobturator sling procedure [7]. In transobturator tape (TOT) placement, through small incisions placed in the groins and in the vagina under the urethra, the mesh can be placed under the urethra in the correct position without having to pass needles blindly through the retropubic space, as in transvaginal tape (TVT). The space that the needle passes through has been extensively studied and has been found to be a very safe space to work in. The mean operative time is significantly shorter in the transobturator sling and risk of bladder injury and of postoperative urinary retention is also considerably lower than other sling procedures. [6] The TOT is a tension-free sling as the resting urethral angle is not changed by the procedure, nor is it necessary to correct urethral hypermobility [8]. One of the most important and not well-recognized advantages of the TOT as compared with other midurethral sling procedures is the lower rate of de novo urge/urge incontinence [9].
The aim of our work is to raise the interest of TOT in the management of stress urinary incontinence in women through a retrospective study.

\section{Methods}

\section{Patient data}

We report retrospective study conducted in the urology department of the Military Hospital Mohammed V-Rabat-MOROCCO over a period of 8 years, from 01/11/2010 to 05/11/2018. Two hundred patients were included in our study. Demographic, clinical and paraclinical characteristics were raised in an exploitation sheet. All the patients diagnosed with SUI had a positive Bonney's test. All patients received a Trans-Obturator Strip according to the OUT-IN method.

A local preparation by oestrogen therapy in the ovum is prescribed one month before the intervention to improve vaginal trophicity.

\section{Preoperative diagnostics}

All patients were urodynamically diagnosed with SUI Patients with mixed or isolated urge incontinence were excluded.

*Correspondence to: Mohammed Mrabti, Military Hospital Mohammed V, Rabat, Morocco, Tel: 00212656954330,E-mail: dr.mohammedmrabti@gmail.com

Key words: stress urinary incontinence, transobturator tape sling, Tension-free vaginal tape

Received: November 08, 2020; Accepted: November 23, 2020; Published: November 27, 2020 
Multichannel urodynamic testing included post void residual urine (PVR) determination, multichannel cystometrogram (CMG), and uroflowmetry. Patients were excluded if PVR exceeded $100 \mathrm{ml}$ or CMG had detrusor overactivity. Mixed incontinence was defined by the presence of sensory urge incontinence or detrusor overactivity as well as stress incontinence during urodynamic examination.

\section{Surgery}

We used two types of polypropylene monofilament sling. As both types of sling were available in our center, the choice of one or another was only determined by the product's presence in the hospital store at each specific moment. The experienced pelvic floor surgeon operated on the women using the technique originally described by Delorme [7]. Anaesthesia was either general or spinal.

\section{Postoperative evaluation}

Intraoperative events including blood loss, time for TOT implantation, any complications, and additional procedures were recorded. Patients were seen at routinely scheduled 12 and 52 weeks postoperatively.

Information regarding continence status was obtained and recorded. Repeat urodynamics were not utilized. Cure was defined as no leakage (dry), or minimal leakage not requiring protection (substantially dry), reported by the patient, along with no leakage seen during an in-office stress test. Also, improvement was defined as a reduction in the use of pads of about $50 \%$ or more. Outcome measures reported include continence status, pad use, urinary urgency, need for medication for urgency, urinary retention (PVR $>100 \mathrm{ml}$ ), and any healing difficulties. All terminology was in accordance with current ICS terminology, except where noted differently [10].

\section{Results}

\section{Age and parity}

The mean age of the patients operated for SUI under this study was 50, 9 years (range 40-72 years). Our patients were large multiparous, the mean number of children was 3.1 (range 3-7 children). Out of the total 200 patients, 116 were menopausal $(56 \%)$ and 62 patients $(31 \%)$ was a Dystocic birth with: (Figure 1)

- Forceps delivery was used in 35 patients (17.5\%)

- Delivery of a macrosomic infant in 22 patients (11\%)

- Post-obstetric perineal tears in 05 patients (2.5\%)

The medical risk factors that were found in our study are: (Figure 2)

- 82 patients $(41 \%)$ were obese with a BMI $>30 \mathrm{~kg} / \mathrm{m} 2$

- 40 patients (20\%) had chronic constipation

- 15 patients (7,5\%) reported a notion of repetitive urinary tract infection

- 10 patients (5\%) were asthmatics

- 20 patients (10\%) followed for type 2 diabetes

36 patients used interventions that could affect pelvic statics:

- 15 patients (7.5\%) had a hysterectomy due to different causes.

- 21 patients or $10.5 \%$ were operated for vaginal prolapse.

The degree of stress urinary incontinence was defined according to the classification of Ingelman-Sundberg and Stamey (Figure 3):
- Degree I: 72 cases (cough or heavy exertion).

- Degree II: 118 cases (leakage to current activity: lifting of load, step, stairway).

- Degree III: 10 cases (permanent leak \pm lying down).

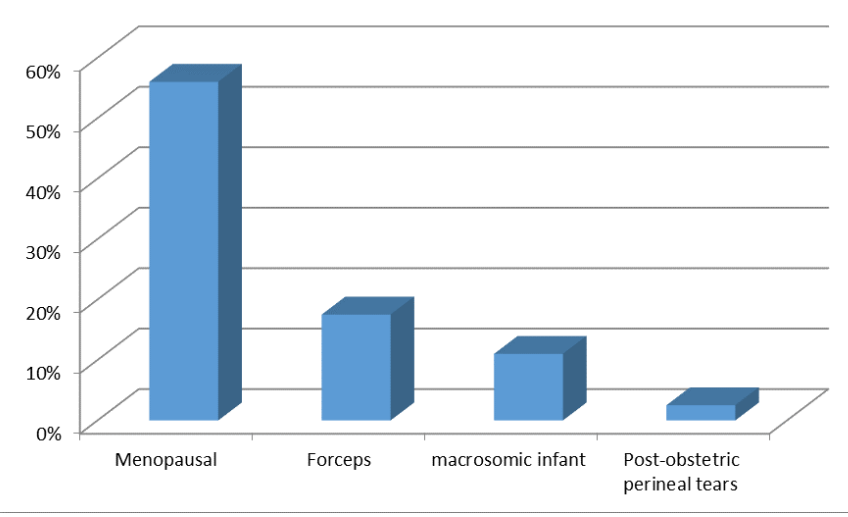

Figure 1. Obstetric gynaecological history

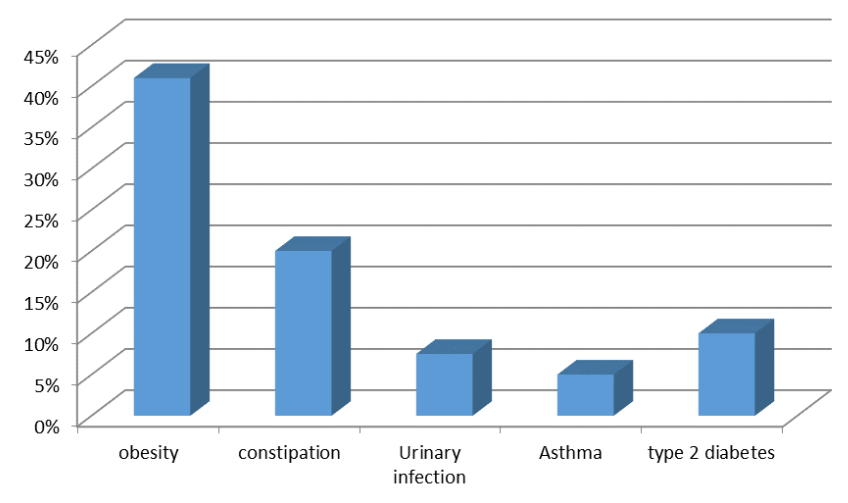

Figure 2. Distribution of medical history by patient

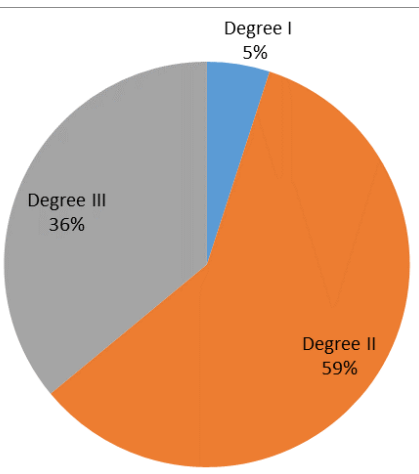

Figure 3. Staging of the degree of incontinence in our patients according to the classification of Ingelman-Sundberg and Stamey

Table 1. Postoperative complication rate was $19.5 \%$

\begin{tabular}{|c|c|c|c|c|}
\hline Minor Bleeding & De-novo urge & Dyspareunia & Residual urine & $\begin{array}{c}\text { Vaginal } \\
\text { Erosion }\end{array}$ \\
\hline 10 & 2 & 1 & 15 & 11 \\
\hline
\end{tabular}




\section{Duration and blood loss in surgery}

The mean duration of surgery was 26.17 minutes, and the mean blood loss was $91.43 \mathrm{ml}$, which was calculated by using pre-weighed swabs. There were no per-operative complications.

\section{Hospital stay}

Postoperative pain management was performed with paracetamol alone in all our patients, there was no need for NSAIDs or opioids analgesia. All our patients were discharged within 24 hours of surgery.

\section{Complications}

Overall complication rate was $19.5 \%$ (39/200) (Table 1). Postoperative temporary voiding difficulty was the main postoperative complication ( $\mathrm{n}=15,7.5 \%)$. No patient showed urine retention in our series. We found appearance of de-novo-urge in 2 women (1\%). 11 patients (5.5\%) had vaginal erosion requiring surgical revision and long-term local care.

\section{Patient's satisfaction}

Majority of women (82\%) are satisfied with the TOT-procedure and recommend the procedure. All regained normal continence without urgency with improved quality of life, while $13 \%$ reported a slight improvement in symptoms. Finally, the intervention was a failure in $5 \%$ of the patients in this study.

\section{Discussion}

Surgical procedures for female SUI aimed to improve the support of the urethrovesical junction and to correct deficient urethral closure. Various surgical techniques were recommended for curing SUI. TVT, as the standard technique for SUI, provided significant cure rates of $86-91 \%$ in both short and long term [11]. However, it had been related with several serious complications, such as bladder perforation, urine retention, retropubic hematoma, bowel perforations, bleeding, and so on [11]. The purpose of TOT was to minimize the incidence of bladder trauma, as well as to possibly decrease postoperative retention [7]. The advantages of this procedure include minimal injury, good tolerance, shorter operative time.

There are several risk factors that can cause or aggravate the SUI in women. Among these factors: age and menopause: indeed, the increase in the prevalence of SUI is relative to age [12]. Studies have shown an increased prevalence of female SUI by age 50 [12]. In our series, $67 \%$ of patients had an age greater than or equal to 50 years, which fits perfectly with literature with a rate of menopausal women of $56 \%$. Obesity: The randomized trial of Subak et al. [13] demonstrates a direct causal link between weight and incontinence. In our series, $41 \%$ of the patients were obese which represents the implication of the overweight. Delivery mode: Obstetrical factors are frequently associated with an increased prevalence of UI [14]. In our series, $31 \%$ of patients had a difficult delivery.

Our retrospective study confirms that TOT stay a safe and effective intervention in the treatment of SUI, with fewer perioperative and post-operative complications.

\section{Vaginal and bladder lesions}

In our series, no bladder or vaginal lesions were raised. These lesions are particularly rare during the TOT, and its mostly reported in case of previous pelvic surgery $[15,16]$, in a randomized multicentre study published by Massimo et al [17], only one out of 75 patients who have benefited from a TOT, had a bladder injury. Morey et al. [16] recommend intraoperative cystoscopy for patients with a history of pelvic surgery.

\section{Vaginal erosion}

Vaginal erosion incidence in our study (5.5\%) is one of the lowest in the literature. In the Massimo study [17], its incidence was $4 \%$. Erosion rates vary depending on the different types of synthetic plates, the operating experience and the procedure. The causes of these erosions can be related to the friction between the plaque and the vaginal epithelium which creates an inflammatory reaction and then a subclinical infection of the prosthetic material with a bad healing thus compromising the vascularization of the tissues.

\section{Dysuria}

Obstructive voiding is one of the most common postoperative complications. Urinary retention was reported in $13.3 \%$ of patients who received TOT in the Tayrac series [6], in the Massimo study [17], the voiding disorder disappeared in $68 \%$ of cases, improved in $25 \%$ of cases and worsened in 7\% (one patient) of the TOT group. In our study, $7.5 \%$ of patients had dysuria with good progression under surveillance.

De novo urgency is considered to be the complication with the greatest negative impact on the quality of life. According to Deval et al [18], the frequency of de novo urgency was three times higher with TVT than with TOT and is related to changes in para-urethral collagen metabolism and sclerosis around the prolene ribbon. Krauth et al. [15] also reported low rate of de-novo urg after TOT (1.6\%). In our study, de novo urgency was present in $1 \%$ of cases (2 patients). Endoscopic exploration showed inflammation of the bladder mucosa, probably due to an inflammatory reaction generated by the passage of the strip by the lateral wall of bladder.

\section{Results on incontinence}

In our study, over a mean duration of 31 months, $82 \%$ of patients regained normal continence with no evidence of urgency with improvement of quality of life, this is among the highest rates of success described in the literature. While 13\% reported a slight improvement in symptoms. Finally, the intervention was a failure in $5 \%$ of the patients in this study. In a retrospective study published by Jeaon et al. [19], out of 97 patients operated for TOT, the success rate was estimated at $34.89 \%$, for these authors, the risk of failure is 4.6 times greater in patients operated by TOT than by the other techniques. These results were confirmed by Schierlitz's study [20].

\section{Conclusion}

TOT seems to be the safest and most effective technique in the treatment of SUI, with minimal complications. The operating time was slightly shorter with TOT, according to the literature, but the length of postoperative stay is short. The major problem of the technique remains the postoperative dysuria and vaginal erosions, which must further push the search in the optimal material for the realization of the strip.

\section{References}

1. Shelton Broome BA (2003) The impact of urinary incontinence on selfefficacy and quality of life. Health Qual Life Outcomes 1: 35. [Crossref]

2. Pan S, Yibo W, Chuiguo H, Wancong W, Naijun Y, et al. (2018) The efficacy and safety comparison of surgical treatments for stress urinary incontinence: A network meta-analysis. Neurourol Urodyn 37: 1199-1211. [Crossref] 
3. Ulmsten U, Henriksson L, Johnson P, Varhos G (1996) An ambulatory surgical procedure under local anesthesia for treatment of female urinary incontinence. Int Urogynecol J Pelvic Floor Dysfunct 7: 81-5. [Crossref]

4. Rezapour M, Ulmsten U (2001) Tension-free vaginal tape (TVT) in women with recurrent stress urinary incontinence - a long term follow up. Int Urogynecol J Pelvic Floor Dysfunct 12: S9-11. [Crossref]

5. Doo CK, Hong B, Chung BJ, Kim JY, Jung HC, et al. (2006) Five-year outcomes of the tension-free vaginal tape procedure for treatment of female stress urinary incontinence. Eur Urol 50: 333-8. [Crossref]

6. deTayrac R, Deffieux X, Derupy S, Chauveaud-Lambling A, Calvanèse-Benamour L, et al. (2004) A prospective randomized trial comparing tension-free vaginal tape and transobturator suburethral tape for surgical treatment of stress urinary incontinence. $\mathrm{Am}$ J Obstet Gynecol 190: 602-8. [Crossref]

7. Delorme E (2001) Transobturator urethral suspension: Mini-invasive procedure in the treatment of stress urinary incontinence in women. Prog Urol 11: 1306-13. [Crossref]

8. Minaglia S, Ozel B, Hurtado E, Klutke CG, Klutke JJ (2005) Effect of Transobturator tape procedure on proximal urethral mobility. Urology 65: 55-9. [Crossref]

9. Juma S, Brito CG (2007) Transobturator tape: Two years follow-up. Neurourol Urodyn 26: 37. [Crossref]

10. Abrams P, Cardozo L, Fall M, Griffiths D, Rosier P, et al. (2002) The standardisation of terminology of lower urinary tract function: report from the standardisation subcommittee of the International Continence Society. Neurourol Urodyn 21: 167-178. [Crossref]

11. Ulmsten U, Falconer C, Johnson P, Jomaa M, Lannér L et al. (1998) A multicenter study of tension-free vaginal tape (TVT) for surgical treatment of stress urinary incontinence. Int Urogynecol Journal Pelvic Floor Dysfunct 9: 210-213. [Crossref]
12. Minassian VA, Stewart WF, Wood GC (2008) Urinary incontinence in women: variation in prevalence estimates and risk factors. Obstet Gynecol 111: 324-31. [Crossref]

13. Subak LL, Wing R, West DS, Franklin F, Vittinghoff E, et al. (2009) Weight loss to treat urinary incontinence in overweight and obese women. $N$ Engl J Med 360: 481-90. [Crossref]

14. Tähtinen RM, Cartwright R, Tsui JF, Aaltonen RL, Aoki Y, et al. (2016) Long-term Impact of Mode of Delivery on Stress Urinary Incontinence and Urgency Urinary Incontinence: A Systematic Review and Meta-analysis. Eur Urol 70: 148-58. [Crossref]

15. Krauth JS, Rasoamiaramanana H, Barletta H, Barrier PY, Grisard-Anaf M, et al. (2005) Suburethral tape treatment of female urinary incontinence - morbidity assessment of the trans-obturator route and a new tape (I-STOPj): a multi-centre experiment involving 604 cases. Eur Urol 47: 102-7. [Crossref]

16. Morey AF, Medendorp AR, Noller MW, Mora RV, Shandera KC, et al. (2006) Transobturator versus transabdominal mid urethral slings: a multiinstitutional comparison of obstructive voiding complications. J Urol 175: 1014-7. [Crossref]

17. Massimo P, Elisabetta C, Bruno F, Antonella G, Stefania R, et al. (2007) Tension-Free Vaginal Tape versus Transobturator Tape as Surgery for Stress Urinary Incontinence: Results of a Multicentre Randomised Trial. Eur Urol 52: 1481-1491. [Crossref]

18. Deval B, Ferchaux J, Berry R, Gambino S, Ciofu C, et al. (2006) Objective and subjective cure rates after trans-obturator tape (OBTAPEj) treatment of female incontinence. Eur Urol 49: 373-7. [Crossref]

19. Sergent F, Popovic I, Sentilhes L, Verspyck E, Lemoine JP, et al. (2004) [Does tensionfree vaginal tape (TVT) have a place in the treatment of sphincter incompetence?] $J$ Gynecol Obstet Biol Reprod 33: 210-20. [Crossref]

20. Schierlitz L, Dwyer PL, Rosamilia A, Murray C, Thomas E, et al. (2008) Effectiveness of tension-free vaginal tape compared with transobturator tape in women with stres urinary incontinence and intrinsic sphincter deficiency: : a randomized controlled trial. Obstet Gynecol 112: 1253-61. [Crossref]

Copyright: (C2020 Mrabti M. This is an open-access article distributed under the terms of the Creative Commons Attribution License, which permits unrestricted use, distribution, and reproduction in any medium, provided the original author and source are credited. 